\title{
Heat Shock Factor-1 Protein in Heat Shock Factor-1 Gene-transfected Human Epidermoid A431 Cells Requires Phosphorylation before Inducing Heat Shock Protein-70 Production
}

\author{
Xuan Z. Ding, George C. Tsokos, and Juliann G. Kiang \\ Department of Clinical Physiology, Division of Medicine, Walter Reed Army Institute of Research, Washington, DC 20307-5100
}

\begin{abstract}
Heat shock factor-1 (HSF1) is a transcriptional factor that binds to heat shock elements located on the promoter region of heat shock protein genes. The purpose of this study was to further investigate the regulation of the expression of the heat shock protein-70 (HSP-70) gene. The HSF1 gene was inserted into pCDNA3 plasmid and then transfected into human epidermoid A431 cells using the $\mathrm{CaOP}_{3}$ method. Control cells were transfected with vector alone. Expression of HSP-70, HSF1, and HSF2 genes and protein were determined. We found a significant increase in the expression of the HSF1 gene, but not HSP-70 and HSF2 genes, in the HSF1 gene-transfected cells. The amount of HSF1-heat shock element complex was significantly increased in both the nucleus and cytosol in HSF1 gene-transfected cells, indicating increased synthesis of HSF1. The amount of HSP-72 in these cells did not change. Therefore, overexpression of HSF1 protein failed to initiate transcription of the HSP-70 gene. Subsequently, we treated the cells with $1 \mu \mathrm{M}$ PMA (a protein kinase $\mathrm{C}$ stimulator), and HSP-70 mRNA and protein were measured at 1 or $4 \mathrm{~h}$ of the treatment, respectively. The levels of both HSP-70 mRNA and HSP-72 protein were significantly increased in nontransfected and transfected cells; the levels of HSP-72 in HSF1 gene-transfected cells were greater than that found in the vector-transfected cells. The PMA-induced increase in HSP-72 protein peaked $8 \mathrm{~h}$ after treatment with PMA and returned to baseline levels at $72 \mathrm{~h}$. This increase was blocked by a PKC inhibitor, staurosporine. After treatment with PMA, HSF1 translocated quickly from cytosol to nucleus. The results suggest that phosphorylation of newly synthesized HSF1 and possibly of other factors are necessary for the induction of HSP-72. Activation of PKC can cause phosphorylation of HSF1, which leads to an enhanced but transient increase in
\end{abstract}

Address correspondence to Dr. Xuan Z. Ding, Department of Clinical Physiology, Division of Medicine, Walter Reed Army Institute of Research, Washington, DC 20307-5100. Phone: (202) 782-3014; FAX: (202) 782-3160.

Received for publication 28 May 1996 and accepted in revised form 17 October 1996.

X.Z. Ding is a Senior National Research Council Fellow. The views presented in this paper are those of the authors; no endorsement by the Department of the Army or the Department of Defense has been given or should be inferred.

The Journal of Clinical Investigation

Volume 99, Number 1, January 1997, 136-143
HSP-70 production. (J. Clin. Invest. 1997. 99:136-143.) Key words: heat shock factor-1 $\bullet$ heat shock protein-70 • gene expression • phorbol-12-myristate-13-acetate - protein kinase A • epithelia

\section{Introduction}

Short exposure of cells to sublethal temperature or to a variety of noxious agents or conditions induces a rapid expression of proteins known as heat shock proteins (HSPs) $)^{1}$ or molecular chaperones $(1,2)$. Recently, HSPs have been found overexpressed in a number of disorders including cardiac hypertrophy, infection, fever, aging, Alzheimer's disease, tumor malignancies, and autoimmune diseases (3-14). Two basic functions have been attributed to HSPs. First, they have been associated with the display of resistance of cells and organs to subsequent injuries mediated by heat, hypoxia, ischemia and reperfusion, infection, ethanol-, and light-induced damages $(5,9,11,15$ 19). Second, they serve as chaperone molecules of various intracellular proteins and may alter their functional characteristics (1).

The promoter region of the HSP gene contains a motif known as heat shock element (HSE), to which heat shock factor-1 (HSF1) binds and promotes its expression (20). The binding of HSF1 to HSE requires its previous activation, which occurs after exposure of cells to heat shock or other environmental stressors, treatment of cells with phorbol esters that activate protein kinase $\mathrm{C}(\mathrm{PKC})$, and/or agents that cause increases in intracellular free calcium concentration $\left(\left[\mathrm{Ca}^{2+}\right]_{i}\right)$ (20-25). It is believed that HSF1 molecules that reside in the cytosol are bound to HSP-70. Under stress, HSF1 separates from HSP-70, forms trimers, translocates to the nucleus, binds to the HSE located on the promoter region of HSP-70 gene, and initiates HSP-70 gene expression (26-29).

It has been reported that overexpression of HSF1 in murine fibroblast cells does not change HSP-70 gene expression, despite the fact that it rendered the cells more resistant to the cytotoxic effects of heat (30). The inability of newly synthesized HSF1 to promote HSP-70 gene expression was not addressed. In this study, we successfully transfected HSF1 gene into human epidermoid A431 cells, which resulted in increases in the HSF1 mRNA and protein. We demonstrate that the HSF1 protein in the HSF1 gene-transfected cells was not active because it did not induce HSP-72 synthesis, an inducible form in the HSP-70 family, and that PKC-mediated phosphorylation of HSF1 protein and possibly of other factors are necessary for the induction of HSP-70 expression.

1. Abbreviations used in this paper: HSE, heat shock element; HSF1, heat shock factor-1; HSP, heat shock protein; PKC, protein kinase C; $\mathrm{RT}$, reverse transcriptase. 


\section{Methods}

Cell culture. Human epidermoid A-431 cells (American Type Culture Collection, Rockville, MD) were incubated at $37^{\circ} \mathrm{C}$ in an atmosphere with $5 \% \mathrm{CO}_{2}$. Cell culture medium was supplemented with DMEM containing $0.03 \%$ glutamine, $4.5 \mathrm{~g} /$ liter glucose, $25 \mathrm{mM}$ Hepes, $10 \%$ FBS, $50 \mu \mathrm{g} / \mathrm{ml}$ penicillin, and $50 \mathrm{U} / \mathrm{ml}$ streptomycin (GIBCO BRL, Gaithersburg, MD). Cells were fed every 3-4 d, and cells from passages 28-45 were used for experiments. All experiments were repeated at least three times.

Transfection. The full-length of the HSF1 gene containing 2,035 bp (a kind gift from Dr. Carl Wu, National Institute of Research, Bethesda, MD) (31) was inserted into pcDNA3 (Invitrogen, San Diego, CA) with EcoRI and BglII restriction enzymes at both sides. The neomycin resistance gene in pcDNA3 was used for the selection of geneticin (G418)-resistant stable cell lines.

Human epidermoid A431 cells were transfected with the HSF1 gene in six-well plates $(5 \mathrm{ml} /$ well $)$ according to the transfection kit protocol $\left(\mathrm{CaOP}_{3}\right.$, GIBCO BRL). The cells were transfected with either the vector alone or the HSF1 gene-carried vector. Cells were incubated with the genes or vector $(15 \mu \mathrm{g}$ of plasmid DNA/well) in HBSP solution containing $12 \mathrm{mM}$ of $\mathrm{CaOP}_{3}$ at $37^{\circ} \mathrm{C}$ for $16 \mathrm{~h}$. The cells were washed twice with medium and incubated in normal medium for $48 \mathrm{~h}$. Subsequently, the cells were cultured in the presence of $200 \mu \mathrm{g} /$ $\mathrm{ml}$ of the antibiotic G418 to select stably transfected cells. The surviving cells were considered to be transfected successfully with the HSF1 gene and were used in the presented experiments. Trypan blue exclusion assay indicated that these gene-transfected cells were viable.

Electrophoretic mobility shift DNA-binding assay of HSF. Nuclear and cytosol extracts from A431 cells were prepared and purified with hypotonic, low, and high salt buffers, according to a method described previously (21). Two complementary single-stranded DNA oligonucleotides, each 36 bases long (synthesized by Midland Certified Reagent Co., Midland, TX) and containing the HSE oligonucleotide, were annealed and used in the electrophoretic mobility shift DNA-binding assay. The DNA sequences were 5'-GAT CCT CGA AGG TTC GAG GAT CCT CGA AGG TTC GAG-3' and $3^{\prime}-$ GAG CTT CCA AGC TCC TAG GAG CTT CCA AGC TCC TAG-5' (32). The HSE was terminally labeled with $\alpha-\left[{ }^{32} \mathrm{P}\right] \mathrm{ATP}$ using T4 polynucleotide kinase. $10 \mu \mathrm{g}$ of either nuclear or cytosol protein was incubated with the $\left[{ }^{32} \mathrm{P}\right] \mathrm{HSE}$ at $30^{\circ} \mathrm{C}$ for $30 \mathrm{~min}$. The HSFHSE binding complex was separated from unbound HSE by $5 \%$ TBE gel (Bio Rad Laboratories, Hercules, CA; 33). The gel was dried and an autoradiogram was prepared. The extent of HSF-HSE binding complex formation was quantified with laser densitometry of the autoradiogram.

Reverse transcriptase PCR (RT-PCR). To measure the mRNA of HSF1, HSF2, HSP-70, and $\beta$-actin, total RNA was isolated with the SATA- $60^{\mathrm{TM}}$ kit (TEL-TEST 'B', Inc., Friendswood, TX; 34). A monolayer of A431 cells $\left(10^{6}\right)$ was trypsinized, homogenized in $1 \mathrm{ml}$ of the extraction solution, and $0.2 \mathrm{ml}$ of chloroform was added. After centrifugation $\left(12,000 \mathrm{~g}, 15 \mathrm{~min}, 4^{\circ} \mathrm{C}\right)$, the supernatant was transferred into a new tube, a half volume of isopropanol was added, and the mixture was centrifuged again. The supernatant was discarded, and the pellet was washed with $75 \%$ ethanol and evaporated to dryness. The pellet was resuspended in $30 \mu \mathrm{H}_{2} \mathrm{O}$, and the total RNA amount and purity were assessed by measuring the optical density at 260/280 nm. mRNA amounts of HSP-70, HSF1, and HSF2 were measured using the RT-PCR method (34). $1 \mu \mathrm{g}$ of total RNA was used for reverse transcription. The reaction mixture contained $1 \times \mathrm{RT}$ buffer, $1 \mu \mathrm{M}$ each of dNTPs, $2.5 \mathrm{U}$ RNAsin, $0.5 \mu \mathrm{g}$ of oligo(dT)-15 primer, $1 \mu \mathrm{g}$ of total RNA, and $15 \mathrm{U}$ of AMV reverse transcriptase (Promega, Madison, WI) in a final volume of $20 \mu \mathrm{l}$. The mixture was incubated at $42^{\circ} \mathrm{C}$ for $20 \mathrm{~min}$. The transcription reaction was terminated by heating the mixture at $95^{\circ} \mathrm{C}$ for $10 \mathrm{~min}$ and then chilling on ice. Four respective pairs of primers specific for HSF1, HSF2, HSP70 , and $\beta$-actin were designed and synthesized as published (34). All primers were 20 bases in length and contained $50 \%$ each of $\mathrm{C}+\mathrm{G}$ and
$\mathrm{A}+\mathrm{T} . \beta$-actin was used as an internal control. $100 \mu \mathrm{l}$ of PCR reaction solution contained $1 \times$ PCR buffer, $3 \mathrm{mM} \mathrm{MgCl}, 400 \mu \mathrm{M}$ dNTPs, 1 $\mu \mathrm{M}$ of each upstream and downstream primers, $2.5 \mathrm{U}$ of AmpliTaq DNA polymerase (Perkin Elmer, Foster City, CA), and $10 \mu \mathrm{l}$ RT mixture. $100 \mu \mathrm{l}$ of mineral oil (Sigma Immunochemicals, St. Louis, $\mathrm{MO})$ were layered on top of the mixture to prevent evaporation during the thermal cycling. 30 PCR cycles were chosen based on the previous experience (34). After amplification, identical volumes of each PCR product were loaded onto $1 \%$ agarose gels prepared with TBE buffer. The gel was stained with $2 \mu l$ ethidium bromide and photographed.

Western blot analysis. Samples were isolated and purified following previously described methods (35). $35 \mu \mathrm{g}$ of proteins from each sample with equal volumes of $2 \times$ loading buffer was boiled for 10 min and each protein then was separated with electrophoresis on $10 \%$ polyacrylamide gel. The samples were electroblotted onto nitrocellulose membranes (Schleicher \& Schuell, Inc., Keene, NH). The blots were preincubated in PBS containing 3\% nonfat dried milk for 90 min at room temperature and then incubated in PBS containing $1 \%$ BSA, $0.1 \%$ thimerosal, and 1:500 mouse mAb against human HSP-72 or human HSF1 (Amersham, Arlington Heights, IL) overnight at $4^{\circ} \mathrm{C}$. After washing with PBS, the blots were incubated in PBS containing 1\% BSA and 1:1,000 rabbit anti-mouse IgG conjugated with peroxidase (Sigma) for $1 \mathrm{~h}$ at room temperature. After washing with PBS containing $0.1 \%$ Tween 20, the blot was incubated with Western blot chemiluminescence reagent (DuPont-NEN, Boston, MA) for $1 \mathrm{~min}$ at room temperature and then exposed to $\mathrm{x}$-ray film. Amounts of HSP-72 and HSF1 were determined by laser densitometry.

Chemicals. PMA and staurosporine were purchased from Sigma, and $\alpha-\left[{ }^{32} \mathrm{P}\right]$ ATP was obtained from DuPont-NEN.

Statistical analysis. All data are expressed as mean \pm SEM. $P<0.05$ is taken to demonstrate the statistical difference. Two-way ANOVA, Studentized-range test, and Newman-Keuls test were used for the comparison of groups (36).

\section{Results}

HSF1 gene transfection into human epidermoid A431 cells induced overexpression of the HSF1 genes, but not HSP-70 and HSF2 genes. To examine whether the transfected HSF1 gene into human A431 cells was transcribed and whether it affected the expression of HSF2 and HSP-70 genes, the mRMA amounts of HSF1, HSF2, and HSP-70 were measured by RTPCR, as described in Methods. Control cells were tested along with cells transfected with the vector alone and with the vector containing the HSF1 gene. The amount of $\beta$-actin mRNA in each sample was measured in parallel and used as an internal control. We found that HSF1 gene expression significantly increased in the HSF1 gene-transfected cells compared with that of either vector-transfected or control cells (Fig. 1). However, the amount of HSP-70 mRNA in the A-431 cells did not increase after HSF1 gene transfection. In addition, neither $\beta$-actin nor HSF2 mRNA expression were affected after transfection with the HSF1 gene (Fig. 1). These results indicate that HSF1 gene transfection into A-431 cells induces the expression of HSF1 mRNA without altering the levels of mRNA for HSP-70 and HSF2 genes.

HSF1 gene transfection is associated with increased levels of HSF1 protein, but not HSP-70 protein. We subsequently asked whether the increased HSF1 gene expression was associated with increased levels HSF1 protein, and whether the HSF1 protein had the ability to bind to the promoter region of the HSP-70 gene and induce its transcription and translation. Nuclear or cytosol extracts were incubated with ${ }^{32} \mathrm{P}$-labeled HSE 


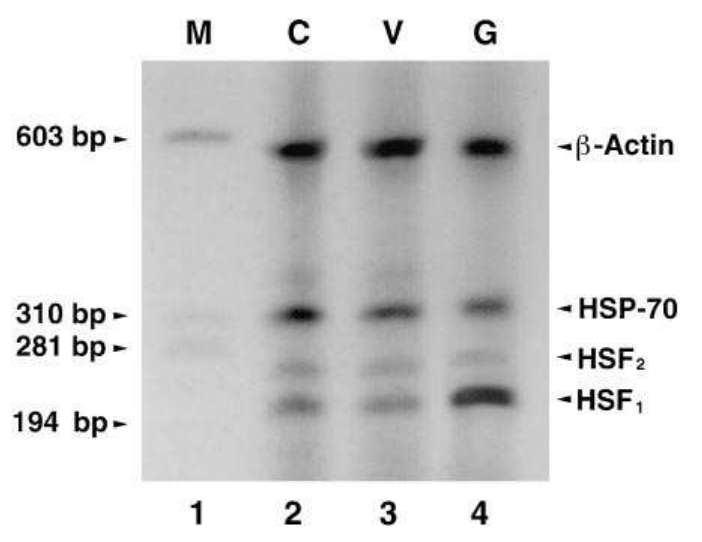

Figure 1. Confirmation of HSF1 gene transfection into human epidermoid A-431 cells. Transfection was carried out as described in Methods. mRNA amounts of HSP-70, HSF1, HSF2, and $\beta$-actin were measured with RT-PCR. The experiment was conducted three times independently and a representative gel is presented. $M$, a marker of 174/HindIII; $C$, nontransfected cells as control; $V$, vector-transfected cells; $G$, HSF1 gene-transfected cells.

for $30 \mathrm{~min}$, and the HSF-HSE complex was subjected to agarose gel electrophoresis. We found that the amount of HSFHSE complex was significantly increased in both nuclear and cytosol extracts from HSF1 gene-transfected A431 cells when compared to those extracted from either control or vectortransfected cells (Fig. 2). Therefore, the HSF1 gene transfection-induced increases in HSF1 mRNA result in increases in HSF1 levels in the nucleus and the cytosol. Because we did not find any increase in HSP-70 gene expression after HSF1 gene transfection, we considered the detected HSF1 to be in an inactive form. Indeed, the amount of HSP-72 that was detected in HSF1 gene-transfected cells by Western blot analysis was not significantly increased when compared with that in control or vector-transfected cells (Fig. 3). These results suggest that HSF1 gene-transfection promotes HSF1 gene expression and

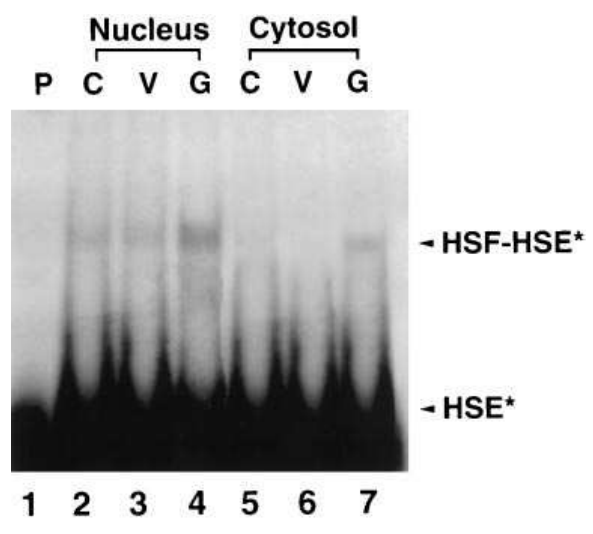

Figure 2. HSF1 increase in HSF1 gene-transfected human epidermoid A-431 cells. Cells were transfected with the HSF1 gene, as described in Methods. The nuclear and cytosol proteins were extracted and incubated with $\left[{ }^{32} \mathrm{P}\right] \mathrm{HSE}\left(H S E^{*}\right)$, and the HSF bound to HSE was measured with gel shift assay. The experiment was conducted three times independently, and a representative gel is presented. $H S F-H S E^{*}$, complex of HSF and ${ }^{32} \mathrm{P}$-labeled HSE*. $P$, HSE* probe only; $C$, nontransfected cells as control; $V$, vector-transfected cells; $G$ : HSF1 gene-transfected cells.

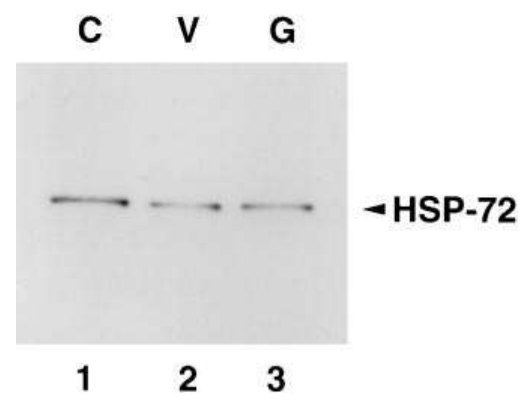

Figure 3. HSP-72 expression in HSF1 gene-transfected human epidermoid A-431 cells. Cells were transfected with vector (alone as a control group) or the HSF1 gene, as described in Methods. After transfection, the HSP-72 amount was analyzed with Western blotting. $35 \mu \mathrm{g}$ of cell extracts were added onto a $10 \%$ polyacrylamide gel. After being transferred to a nitrocellulose membrane, the blot was incubated in PBS containing 3\% nonfat dried milk for $60 \mathrm{~min}$ at room temperature, and was incubated with mouse $\mathrm{mAb}$ against human HSP- 72 at $4^{\circ} \mathrm{C}$ overnight and with rabbit anti-mouse IgG conjugated with peroxidase for $1 \mathrm{~h}$ at room temperature. The HSP-72 amount was demonstrated with chemiluminescence. The experiment was conducted three times independently, and a representative Western blot is presented. $C$, nontransfected cells as control; $V$, vector-transfected cells; $G$, HSF1 gene-transfected cells.

protein synthesis that do not promote HSP-72 gene transcription and protein synthesis despite the fact that it binds to the HSE.

Activation of PKC stimulates HSP-72 synthesis in HSF1 gene-transfected cells. It has been known that activation of PKC induced by PMA leads to the activation of HSF1 and increases the synthesis of HSP-72 (21). We considered that exposure of HSF1 gene-transfected cells to PMA could lead to phosphorylation of the overproduced HSF1 protein, followed by induction of HSP-70 synthesis. Control, vector, and HSF1 gene-transfected cells A-431 cells were treated with $1 \mu \mathrm{M}$ PMA for $1 \mathrm{~h}$, and the mRNA amounts of HSF1, HSF2, and HSP-70 were measured using RT-PCR. Treatment of A-431 cells with PMA had been found to efficiently activate HSF1 and induce increases in HSP-72 (21). As expected, treatment of control and vector-transfected cells with PMA induced increased amounts of both HSF1 and HSP-70 mRNA (Fig. $4 A$, lanes 4 and 5 vs. lanes 1 and 2). Interestingly, the amount of HSP-70 mRNA was higher in the PMA-treated, HSF1 genetransfected cells than in the two control cells mentioned above (Fig. $4 \mathrm{~A}$, lane 6 vs. lanes 4 and 5), whereas the amount of HSF1 mRNA was not increased further in these cells after PMA treatment (Fig. $4 A$, lane 6 vs. lane 3 ). Treatment of either of the three cell groups with PMA did not significantly change HSF 2 or $\beta$-actin mRNA expression.

To determine whether the PMA-induced increase in HSP70 gene expression was associated with an increase in HSP-72 protein synthesis in HSF1 gene-transfected cells, HSP-72 protein levels were measured with Western blot analysis after the treatment of cells with $1 \mu \mathrm{M}$ PMA for $4 \mathrm{~h}$. Again, as expected, we observed that PMA induced a significant increase in the levels of HSP-72 protein in both control and vector-transfected cells (Fig. $4 \mathrm{~B}$ ). The HSP-72 protein levels were found to be significantly increased in the PMA-treated, HSF1 gene-transfected cells when compared to control cells that were not treated with PMA. In addition, PMA induced the highest levels of HSP-72 in the HSF1 gene-transfected cells. 
A

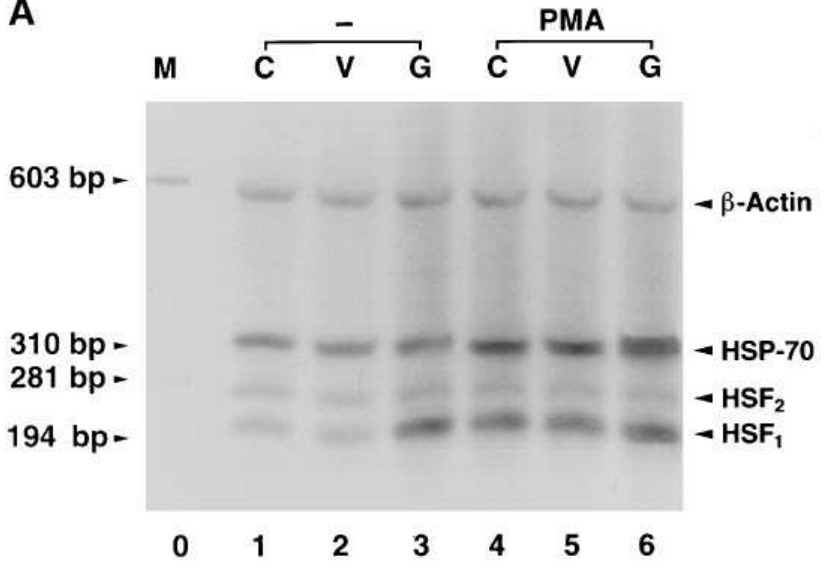

B

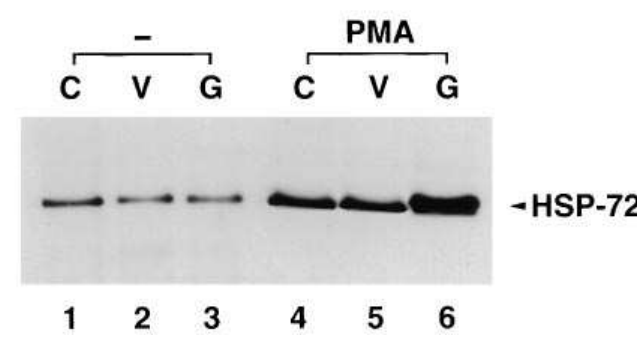

Figure 4. Increases in HSP-70 gene expression and protein synthesis by PMA in HSF1 gene-transfected human epidermoid A-431 cells. Nontransfected $(C)$, vector-transfected $(V)$, and HSF1 gene-transfected cells $(G)$ were treated with $1 \mu$ M PMA for $1 \mathrm{~h}$. $(A)$ Total RNA was isolated as described in methods. The OD value of each sample was determined, and equal amounts of RNA were used as a template for reverse transcription. The mRNAs of HSP-70, HSF1, and HSF2 were amplified with PCR. $\beta$-actin was used as an internal control. $(B)$ HSP-72 amount was measured using Western blotting. The experiment was conducted three times independently, and a representative gel or Western blot is presented. $M$, a marker of 174/HindIII.

PMA induced-increase in HSP-72 expression in HSF1 gene-transfected cells was time dependent and transient. To examine whether the duration of exposure of cells to PMA was important in the induction of increases in HSP-72 protein expression in HSF1 gene-transfected cells, HSP-72 protein levels were detected in vector- and HSF1 gene-transfected cells after treatment with $1 \mu \mathrm{M}$ PMA for $0,1,2,4,8$, and $24 \mathrm{~h}$. HSP-72 amounts in both groups of cells started to increase at $4 \mathrm{~h}$, reached a maximal level at $8 \mathrm{~h}$, and returned to baseline levels at $24 \mathrm{~h}$ (Fig. 5). HSP-72 expression in PMA-treated HSF1 gene-transfected cells was greater than that found in vectortransfected cells treated with PMA (Fig. 5).

To determine whether the PMA-induced increase in HSP72 protein in HSF1-transfected A431 cells was transient, both vector- and HSF1 gene-transfected cells were incubated with 1 $\mu \mathrm{M}$ PMA for $4 \mathrm{~h}$, and the cells were washed twice with media and then further incubated in medium up to $72 \mathrm{~h}$. Protein samples were extracted from these cells at different time points before and after the PMA treatment, and the HSP-72 protein levels were measured by Western blot analysis. It was found that HSP-72 protein levels in both groups of cells were significantly increased after the $4 \mathrm{~h}$ of incubation with PMA. The increase in HSP-72 protein levels continued and reached maxi-

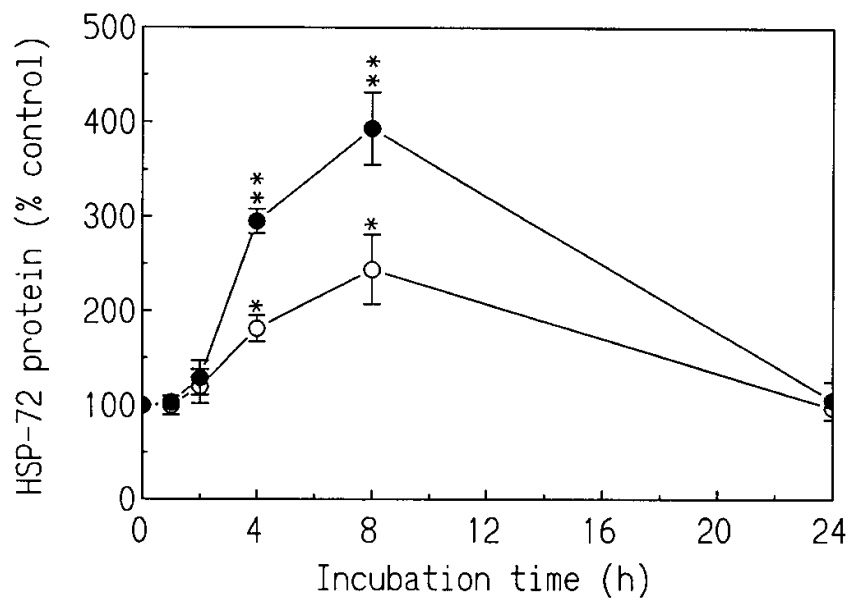

Figure 5. Time course of PMA-induced increases in HSP-72 in HSF1 gene-transfected human epidermoid A- 431 cells. Cells were treated with $1 \mu \mathrm{M}$ PMA for $0,1,2,4,8$, and $24 \mathrm{~h}$, and protein samples were collected. The same amount of proteins of each sample was loaded to $10 \%$ SDS-PAGE. HSP-72 amount was measured using Western blots and was quantified densitometrically. The experiment was conducted three times independently. The data were expressed as percent of levels found at $t=0$. $* P<0.05$ vs. vector-transfected cells at $t=0$; ** $P<0.05$ vs. the vector-transfected at the correspondent time point and HSF1 gene-transfected cells at $t=0$, determined by two-way ANOVA and Studentized-range test. - $\bigcirc$ - vector transfection;

- HSF1 gene transfection.

mum levels within the next $4 \mathrm{~h}$ in both groups of cells (Fig. 6). The level of HSP-72 amount in HSF1 gene-transfected cells was again greater than that observed in vector-transfected cells after PMA treatment. The recovery time in both groups was

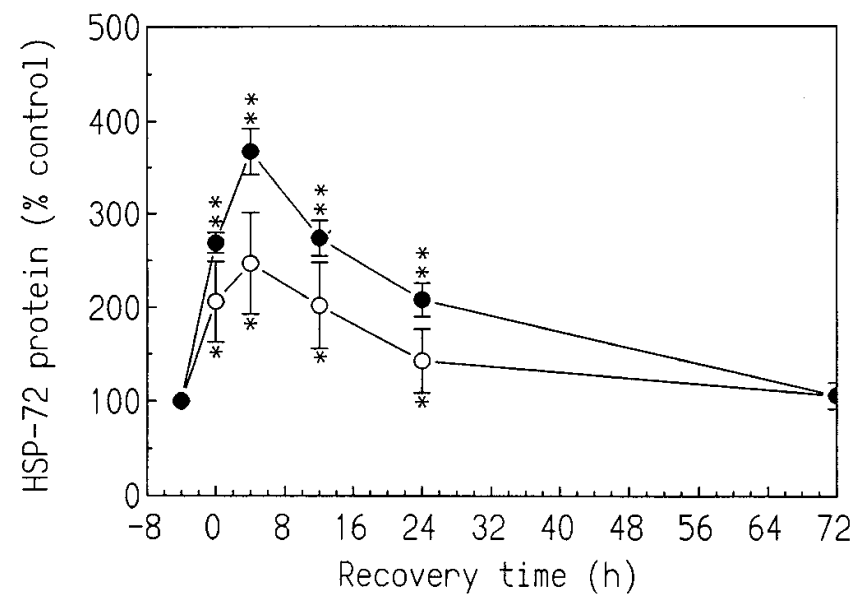

Figure 6. Recovery of increased HSP-72 induced by PMA in HSF1 gene-transfected human epidermoid A-431 cells. Cells were pretreated with $1 \mu \mathrm{M}$ PMA for $4 \mathrm{~h}$ and washed twice with media. Protein samples were collected from cells at $0,4,12,24$, and $72 \mathrm{~h}$. The same amount of proteins from each sample was loaded to $10 \%$ SDSPAGE. HSP-72 amount was measured using Western blots and was quantified densitometrically. The experiment was conducted three times independently. The data were expressed as percent of levels found at $t=0 . * P<0.05$ vs. vector-transfected cells at $t=-4 \mathrm{~h}$; $* * P<0.05$ vs. the vector-transfected at the correspondent time point and HSF1 gene-transfected cells at $t=0$, determined by two-way ANOVA and Studentized-range test. - $\bigcirc$ - vector transfection;

- HSF1 gene transfection. 


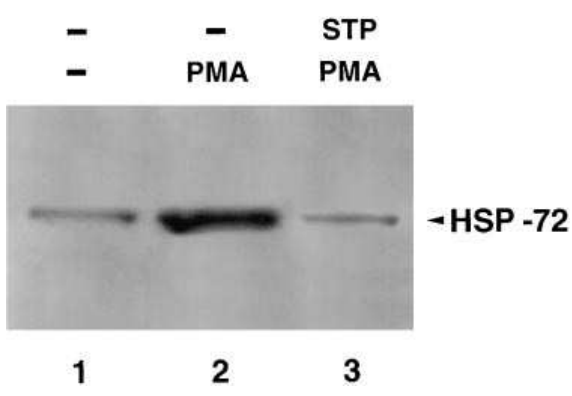

Figure 7. Staurosporine blocked the PMA-induced increases in HSP72 synthesis in HSF1 gene-transfected human epidermoid A-431 cells. HSF1 gene-transfected cells were treated with $0.1 \mu \mathrm{M}$ staurosporine for $15 \mathrm{~min}$ before treatment with $1 \mu \mathrm{M}$ PMA for $4 \mathrm{~h}$. The amount of HSP-72 was measured using Western blots. The experiment was conducted three times independently, and a representative Western blot is presented. -, no drug treatment; $S T P$, staurosporine.

similar; it started at $12 \mathrm{~h}$ and returned to baseline levels at $72 \mathrm{~h}$. Therefore, treatment of HSF1 gene-transfected cells with PMA is associated with a transient increase in HSP-72 protein.

$P M A$-induced increases in HSP-72 expression involved $P K C$. To determine whether the PMA-induced increase in HSP-72 synthesis was mediated specifically by activated PKC, HSF1 gene-transfected cells were treated with staurosporine, an antagonist of PKC, at $0.1 \mu \mathrm{M}$ for $15 \mathrm{~min}(8)$ before treatment with $1 \mu \mathrm{M}$ PMA for $4 \mathrm{~h}$. Western blot analysis (Fig. 7) shows that staurosporine inhibited the PMA-induced increase in HSP-72. This finding further supports that the PMA-induced increase in HSP-72 is mediated by activation of PKC.

The increase in HSP-72 by PMA was mediated by phosphorylation and translocation of HSF1 in gene-transfected cells. We have observed that activation of PKC with PMA induced the translocation of HSF1 from cytosol to nucleus within $1 \mathrm{~h}$, leading to the initiation of the transcription of HSP-70 gene expression. Phosphorylation and translocation of HSF1 in HSF1 gene-transfected cells was investigated. The cells were incubated with $1 \mu \mathrm{M}$ PMA for $1 \mathrm{~h}$. Nuclear and cytosol proteins were extracted and blotted with an antibody against HSF1. Two bands were observed in the nucleus. The upper band represents the phosphorylated form (Fig. 8, lanes 2-7) because it disappeared after treatment with phosphorylase (data not shown). The lower band, which represents the unphosphorylated form of HSF1, was observed in the cytosol (lanes 9, 11, and 13) and nuclear extracts (lanes 2-7). The levels of cytosol and nuclear HSF1 in HSF1 gene-transfected cells (lane 13) significantly increased when compared to those of control (lane 9) and vector-transfected cells (lane 11). Treatment with PMA resulted in no detectable HSF1 in the cytosol (lanes 10, 12, and 14) and increases in nuclear phosphorylated and unphosphorylated HSF1 (lanes 3, 5, and 7), suggesting that translocation from cytosol to nucleus had occurred. However, a greater increase in nuclear HSF1 in HSF1 gene-transfected cells (lane 7) than that in control (lane 3) and vector-transfected cells (lane 5) was observed.

PMA-induced phosphorylation and translocation of HSF1 involved $P K C$. To confirm that the PMA-induced phosphorylation and translocation of HSF1 were mediated by activated PKC, we investigated the effect of staurosporine on PMAinduced phosphorylation and translocation of HSF1 in control, vector-, and HSF1 gene-transfected cells. The cells were incubated with $0.1 \mu \mathrm{M}$ staurosporine for $15 \mathrm{~min}$ before treatment with $1 \mu \mathrm{M}$ PMA for $1 \mathrm{~h}$. The amount and phosphorylation of HSF1 were measured in both the cytosol and the nucleus with Western blot analysis. Fig. 9 shows that staurosporine totally blocked the PMA-induced the translocation of HSF1 from the cytosol to the nucleus, as well as the phosphorylation of nuclear HSF1, in all three kinds of cells. Staurosporine alone had no effect on the phosphorylation and the translocation of HSF1. These results indicate that the PMA-induced phosphorylation and translocation of HSF1 were mediated by the activation of PKC.

\section{Discussion}

The present study demonstrates that the HSF1 gene was successfully transfected into human epidermoid A-431 cells. Increased HSF1 gene expression and protein synthesis in these transfected cells failed to induce HSP-70 production. Treatment of HSF1 gene-transfected cells with PMA activated HSF1, promoted its translocation from cytosol to nucleus, and subsequently increased HSP-70 expression.

The expression of HSP-70 can be readily induced by exposing cells or tissues to sublethal heat for a short time, such as

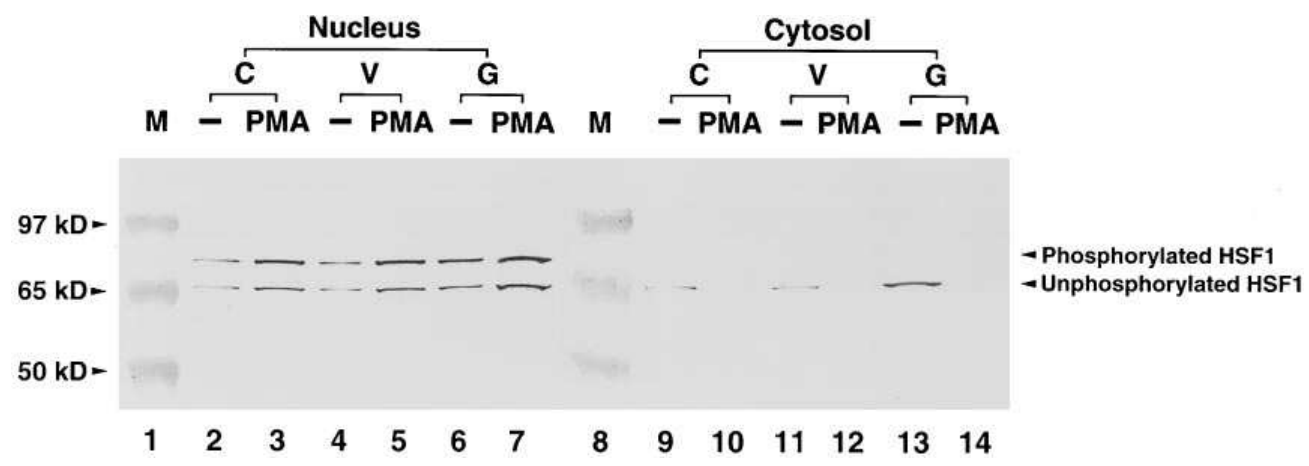

Figure 8. PMA-promoted HSF1 translocation and phosphorylation in HSF1 genetransfected human epidermoid A-431 cells. Cells were treated with $1 \mu \mathrm{M}$ PMA for $1 \mathrm{~h}$. The amount of HSF1 in HSF1 genetransfected cells was measured using Western blots. Both nuclear and cytosol proteins were extracted. $35 \mu \mathrm{g}$ of each sample was added onto a $10 \%$ polyacrylamide gel. After being transferred to a nitrocellulose membrane, the blot was incubated in PBS containing 3\% nonfat dried milk for $60 \mathrm{~min}$ at room temperature, rabbit antibody against human HSF1 at $4^{\circ} \mathrm{C}$ overnight, and goat anti-rabbit IgG conjugated with phosphatase for $1 \mathrm{~h}$ at room temperature. The HSF1 amount was demonstrated with development of red color in the presence of substrate solution. $M$, molecular weight markers; $C$, nontransfected cells as control; $V$, vector-transfected cells; $G$, HSF1 gene-transfected cells. The experiment was conducted three times. -, no drug treatment. 

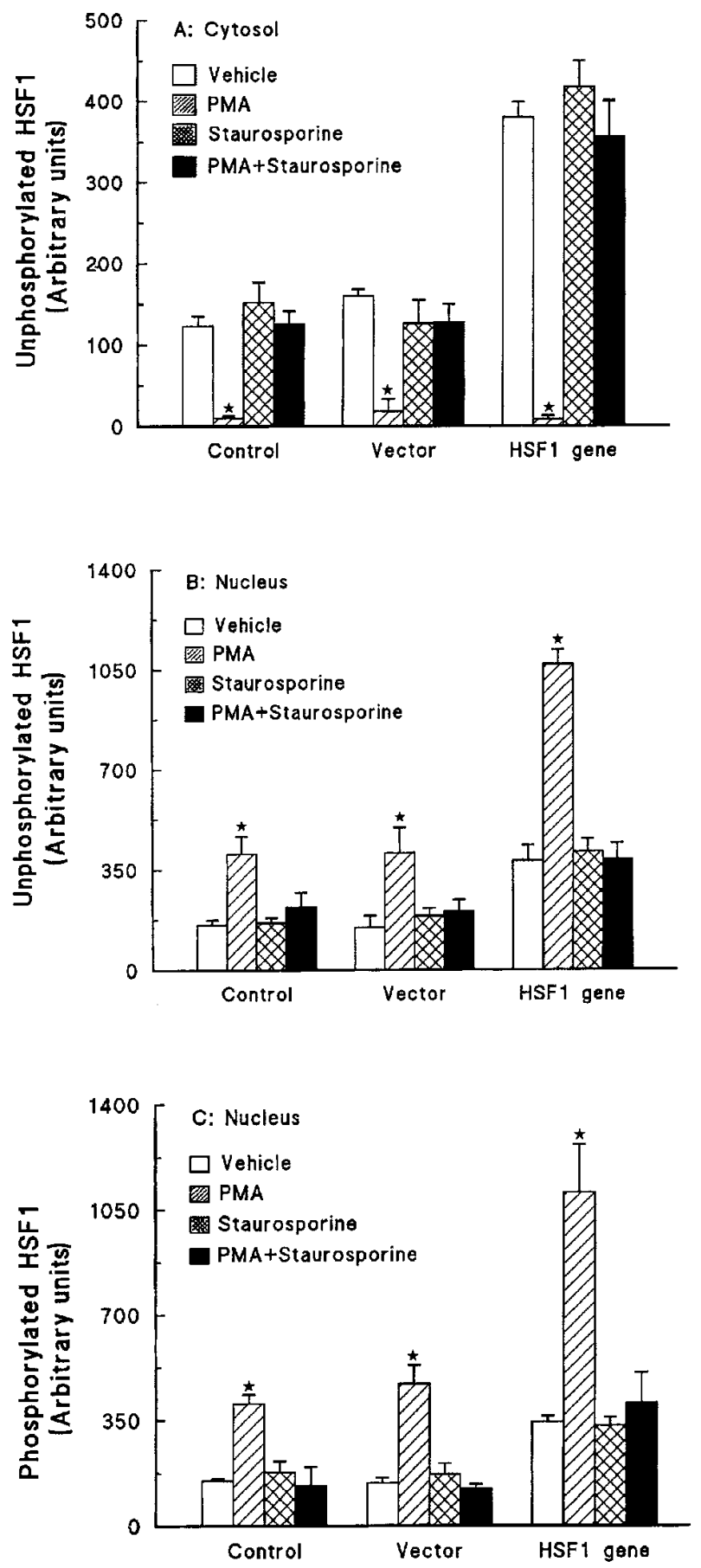

Figure 9. Staurosporine blocked the PMA-induced translocation and phosphorylation of HSF1. Control, vector-, and HSF1 gene-transfected cells were treated with $0.1 \mu \mathrm{M}$ staurosporine for $15 \mathrm{~min}$ before treatment with $1 \mu \mathrm{M}$ PMA for $1 \mathrm{~h}$. The amount and phosphorylation of HSF1 were measured using Western blots. The same amount of proteins of each sample was loaded to $10 \%$ SDS PAGE. The experiment was conducted three times independently, and data were presented using arbitrary units. $* P<0.05$ vs. vehicle-, PMA-, and staurosporine plus PMA-treated cells, determined by two-way ANOVA and Newman-Keuls test.

$42-45^{\circ} \mathrm{C}$ for $10-45 \mathrm{~min}(16)$. Agents that interfere with the cell signaling process can also induce the expression of HSP-70. Specifically, activation of PKC by PMA and increases in intracellular $\mathrm{Ca}^{2+}$ by ionomycin induce HSP-70 production $(21,37-$
41). Apparently, the PMA-induced HSF1 phosphorylation and increase in $\left[\mathrm{Ca}^{2+}\right]_{i}$ by ionomycin promote translocation of HSF1 from cytosol to nucleus, leading to HSF1 binding to HSE on the promoter region of the HSP-70 gene. Interestingly, PMA and ionomycin also cause increased HSF1 mRNA and protein expression. In contrast, HSF2, which is $75 \%$ homologous to HSF1, was not altered by treatment with PMA or ionomycin (21).

Phosphorylation of HSF1 occurs in response to heat (37, 40-42) or inducers of transcriptional activation such as cadmium and arachidonic acid $(35,43)$. Although the level of HSF1 phosphorylation is thought to be associated with its ability to induce the expression of HSP-70, the amino acid analogue azetidine, which induces HSP-70 gene transcription, does not cause HSF1 phosphorylation (29). In HeLa cells, the induction of HSP does not require phosphorylation of the serine and threonine residues of HSF1 (44). Additionally, phosphorylation of yeast HSF1 may facilitate its binding to HSE-containing oligonucleotide, but may not increase its activity (45). These discrepancies may result from the fact that they were performed in different cell types and/or the possibility that other factors besides HSF1 are involved in the initiation and regulation of HSP-70 expression.

We have transfected human epidermoid cells with the HSF1 gene to further address the mechanisms that pertain to the HSF1-mediated regulation of HSP-70 expression. Our experiments show that HSF1 is present in the cytosol and the nucleus of untransfected cells. Only the unphosphorylated form was observed in the cytosol, whereas the phosphorylated and the unphosphorylated forms were detected in the nucleus (Fig. 8). It is believed that the phosphorylated HSF1 maintains the basal level of the constitutively expressed HSP-70. In HSF1 gene-transfected cells, however, phosphorylation and translocation of HSF1 are necessary for synthesizing new HSP-72. This view is supported by the following facts: (a) HSF1 gene transfection increased HSF1 protein, but not HSP-72; (b) treatment with the PKC activator PMA resulted in a significant translocation of HSF1 from the cytosol to the nucleus; (c) PMA induced HSP-72 production without altering HSF1 production in the HSF1 gene-transfected cells; $(d)$ staurosporine prevented the PMA-induced phosphorylation of HSF1 in the nucleus; and (e) staurosporine inhibited the PMA-induced increase in HSP-72. No hyperphosphorylated form of HSF1 was found in the nucleus because PMA did not cause a change in the molecular weight of the phosphorylated form of HSF1 (Fig. 8).

The fact that the constitutive increased levels of nuclear phosphorylated HSF1 in the HSF1 gene-transfected cells were not associated with increased expression of HSP-72 (Figs. 2, 4 $B$, and 8 ) suggests that other events besides phosphorylation and translocation of HSF1 are involved in the initiation and regulation of HSP-70 expression. Several possibilities can be considered. First, certain critical concentration of the HSF1 in the nucleus is required before the induction of increased HSP-70 gene transcription. This explanation is not likely because the heat- or the PMA-induced phosphorylation and translocation of constitutive HSF1 in control cells are sufficient to induce significant increases in the transcription of HSP-70. It should be noted that the levels of HSE-binding protein in PMA-treated control cells is comparable to those in non-PMA-treated HSF1 gene-transfected cells. Second, PMA can cause the phosphorylation of other transcription factors 
that must act in concert with phosphorylated HSF1. These other yet unidentified factors act by binding to other sites of the promoter region of the HSP-70 gene and regulating the initiation of HSP-70 transcription. Our data cannot exclude this possibility, and more studies are needed to further dissect this possibility. Third, PMA may cause the phosphorylation of other nuclear proteins that bind to HSF1. Again, our previous data did not support this possibility because only one band of HSF1-HSE complex was observed (21). Last, it has been shown that activated HSF1 forms trimers $(26,27,29)$. The translocation of the trimers depends on increased $\left[\mathrm{Ca}^{2+}\right]_{\mathrm{i}}$, and the HSF1 gene-transfected cells displayed a resting $\left[\mathrm{Ca}^{2+}\right]_{\mathrm{i}}$ comparable to that found in vector-transfected cells. Because PMA has been shown to increase $\left[\mathrm{Ca}^{2+}\right]_{i}$ by increasing $\mathrm{Ca}^{2+}$ entry from external sources (21), it is possible that $\mathrm{Ca}^{2+}$ may provide the additional signal in the initiation of HSP-70 transcription.

The PMA-stimulated induction of HSP-72 in HSF1 genetransfected cells is transient. It is still unknown whether or not the overexpression of HSP-72 is associated with any side effects or abnormal cell function. Although no causal relationship has been provided so far, increased levels of various types of HSP have been found in cells and tissues from patients with autoimmune (46) and degenerative diseases (3). In considering the genetic transfer of genes that may provide cell protection, the duration of protein expression is important. Along these lines, the use of the HSF1 gene in establishing or increasing the resistance of cells against noxious stimuli by the enhanced, but transient, increase in HSP-72 production serves as a tool in attaining cell protection.

In summary, increased expression of HSF1 in HSF1 genetransfected cells is not associated by increased production of HSP-72. A second signal that is provided by the PMA-induced, activated PKC and that includes, but is not limited to, the phosphorylation of the HSF1 is necessary. The activated HSF1 quickly translocated from cytosol to nucleus and initiated HSP-70 gene expression and protein synthesis. The newly synthesized HSP-72 is enhanced but transient.

\section{Acknowledgments}

The authors thank Dr. C. Wu for his kind gift of the HSF1 gene.

This work was supported by the Department of the Army RAD II STO C.

\section{References}

1. Morimoto, R., A. Tissieres, and Georgopoulos. 1994. Progress and perspectives on the biology of heat shock proteins and molecular chaperones. In The Biology of Heat Shock Proteins and Molecular Chaperones. R.I. Morimoto et al., editors. Cold Spring Harbor Laboratory Press, Cold Spring Harbor, NY. 1-30.

2. Schlesinger, M.J. 1990. Heat shock proteins. J. Biol. Chem. 265:1211112114.

3. Dewji, N.N., C. Do, and R.M. Bayney. 1995. Transcriptional activation of Alzheimer's B-amyloid precursor protein gene by stress. Mol. Brain Res. 33: 245-253.

4. Blake, M.J., R. Udelsman, G.J. Feulner, D.D. Norton, and N.J. Holbrook. 1991. Stress-induced heat shock protein 70 expression in adrenal cortex: an adrenocorticotropic hormon-sensitive, age-dependent response. Proc. Natl. Acad. Sci. USA. 88:9873-9877.

5. Currie, R.W., M. Karmazyn, M. Klco, and K. Mailer. 1988. Heat shock response is associated with enhanced post-ischemic ventricular recovery. Circ. Res. 63:543-549.

6. Fargnoli, J., T. Kunisada, A.J. Fornace, Jr., E.L. Schneider, and N.J. Holbrook. 1990. Decreased expression of heat shock protein 70 mRNA and protein after heat treatment in cells of aged rats. Proc. Natl. Acad. Sci. USA. 87:846850.

7. Holbrook, N.J., and R. Udelsman. 1994. Heat shock protein gene expression in response to physiologic stress and aging. In The Biology of Heat Shock Proteins and Molecular Chaperones. R.I. Morimoto, A. Tissières, and C. Georgopoulos, editors. Cold Spring Harbor Laboratory Press, Cold Spring Harbor, NY. 577-593.

8. Kaufmann, S.H.E. 1990. Heat shock proteins and the immune response. Immunol. Today. 11:129-136.

9. Perdrizet, G.A., H. Kaneko, T.M. Buckley, M.A. Fishman, and R.T. Schweizer. 1990. Heat shock protects pig kidneys against warm ischemic injury. Transplant. Proc. 22:460-461.

10. Polla, B.S., A.M. Healy, W.C. Wojno, and S.M. Kerane. 1987. Hormone 1, 25-dihydroxyvitamin D3 modulates heat shock response in monocytes. Am. J. Physiol. 252:C640-C649.

11. Stojadinovic, A., J.G. Kiang, R.C. Smallridge, R.G. Galloway, and T. Shea-Donohue. 1995. Induction of heat shock protein-72 protects against ischemia/reperfusion injury in rat small intestine. Gastroenterology. 109:505-512.

12. Sugawara, S., K. Takeda, A. Lee, and G. Dennert. 1993. Suppression of stress protein GRP78 induction in tumor B/C10ME eliminates resistance to cell mediated cytotoxicity. Cancer Res. 53:6001-6005.

13. Villar, J., S.P. Ribeiro, J.B.M. Mullen, M. Kuliszewski, M. Post, and A.S Slutsky. 1994. Induction of heat shock response reduces mortality rate and organ damage in a sepsis-induced acute lung injury model. Crit. Care Med. 22: 914-921.

14. Yong, D.B., A. Mehlert, and D.F. Smith. 1990. Stress protein and infectious diseases. In Stress Proteins in Biology and Medicine. R.I. Morimoto et al., editors. Cold Spring Harbor Laboratory Press, Cold Spring Harbor, NY. 131166.

15. Barbe, M.F., M. Tytell, D.J. Gower, and W.J. Welch. 1988. Hyperthermia protects against light damage in the rat retina. Science (Wash. DC). 241: 1817-1820.

16. Kiang, J.G., X.D. Wang, X.Z. Ding, I. Gist, and R.C. Smallridge. 1996. Heat shock inhibits the hypoxia-induced effects in rat thyroid FRTL-5 cells. Thyroid. 6:475-483.

17. Kiang, J.G., and M.L. Koenig. 1996 Characterization of intracellular calcium pools and their desensitization in thermotolerant human A-431 cells. J. Invest. Med. 44:352-361.

18. Mestril, R., S.H. Chi, M.R. Sayen, and W.H. Dillmann. 1994. Isolation of a novel inducible rat heat-shock protein (HSP70) gene and its expression during ischaemia/hypoxia and heat skock. Biochem. J. 298:561-569.

19. Nakamura, K., K. Rokutan, N. Marui, A. Aoike, and K. Kawai. 1991. Induction of heat shock proteins and their implication in protection against ethanol-induced damage in cultured guinea pig gastric mucosal cells. Gastroenterology. 101:161-166.

20. Wu, C., J. Clos, G. Giorgi, R.I. Haroun, S.J. Kim, S.K. Rabindran, J.T. Westwood, J. Wisniewski, and G. Yim. 1994. Structure and regulation of heat shock transcription factor. R.I. Morimoto et al., editors. Cold Spring Harbor Laboratory Press, Cold Spring Harbor, NY. 395-416.

21. Ding, X.Z., R.C. Smallridge, R.J. Galloway, and J.G. Kiang. 1996. Increase in HSF1 translocation and synthesis in human epidermoid A431 cells: role of protein kinase $\mathrm{C}$ and $\left[\mathrm{Ca}^{2+}\right]_{\mathrm{i}}$. J. Invest. Med. 44:144-153.

22. Hosokawa, N., K. Hirayoshi, H. Kudo, H. Takechi, A. Aoike, K. Kawai, and K. Nagata. 1992. Inhibition of the activation of heat shock factor in vivo and in vitro by flavonoids. Mol. Cell. Biol. 12:3490-3498.

23. Kim, D., H. Ouyang, and G.C. Li. 1995. Heat shock protein hsp70 accelerates the recovery of heat-shocked mammalian cells through its modulation of heat shock transcription factor HSF1. Proc. Natl. Acad. Sci. USA. 92:2126-2130.

24. Mosser, D.D., P.T. Kotzbauer, K.D. Sarge, and R.I. Morimoto. 1990. In vitro activation of heat shock transcription factor DNA-binding by calcium and biochemical conditions that affect protein conformation. Proc. Natl. Acad. Sci. USA. 87:3748-3752.

25. Why, S.K.V., A.S. Mann, G. Thulin, X.H. Zhou, M. Kashgarian, and N.J. Siegel. 1994. Activation of heat shock transcription factor by graded reductions in renal ATP, in vivo, in the rat. J. Clin. Invest. 94:1518-1523.

26. Kroeger, P.E., K.D. Sarge, and R.I. Morimoto. 1993. Mouse heat shock transcription factors 1 and 2 prefer a trimeric binding site but interact differently with the HSP70 heat shock element. Mol. Cell. Biol. 13:3370-3383.

27. Morimoto, R.I., D.A. Jurivich, P.E. Kroeger, S.K. Mathur, S.P. Murphy, A. Nakai, K. Sarge, K. Abravaya, and L.T. Sistonen. 1994. Regulation of heat shock gene transcription by a family of heat shock factors. R.I. Morimoto et al., editors. Cold Spring Harbor Laboratory Press, Cold Spring Harbor, NY. 417-455.

28. Mosser, D.D., J. Duchaine, and B. Massie. 1993. The DNA-binding activity of the human heat shock transcription factor is regulated in vivo by hsp70. Mol. Cell. Biol. 13:5427-5438.

29. Sarge, K.D., S.P. Murphy, and R.I. Morimoto. 1993. Activation of heat shock gene transcription by heat shock factor 1 involves oligomerization, acquisition of DNA-binding activity, and nuclear localization and can occur in the absence of stress. Mol. Cell. Biol. 13:1392-1407.

30. Mivechi, N.F., and A.J. Giaccia. 1995. Mitogen-activated protein kinase acts as a negative regulator of the heat shock respose in NIH3T3 cells. Cancer Res. 55:5512-5519. 
31. Rabindran, S.K., G. Giorgi, J. Clos, and C. Wu. 1991. Molecular cloning and expression of a human heat shock factor, HSF1. Proc. Natl. Acad. Sci. USA. 88:6906-6910.

32. Abravaya, K., B. Philips, and R.I. Morimoto. 1991. Heat shock-induced interactions of heat shock transcription factor and the human hsp70 promoter examined by in vivo footprinting. Mol. Cell. Biol. 11:586-592.

33. Ausubel, F.M., R. Brent, R.E. Kingston, D.D. Moore, J.G. Seidman, J.A. Smith, and K. Struhl. 1994. Current Protocols in Molecular Biology. Vol. 2. 12.2.1-12.2.7.

34. Ding, X.Z., R.C. Smallridge, R.J. Galloway, and J.G. Kiang. 1996. Rapid assay of HSF1 and HSF2 gene expression by RT-PCR. Mol. Cell. Biochem. 158:189-192.

35. Kiang, J.G., F.E. Carr, M.R. Burns, and D.E. McClain. 1994. HSP-72 synthesis is promoted by increase in $\left[\mathrm{Ca}^{2+}\right]_{\mathrm{i}}$ or activation of $\mathrm{G}$ proteins but not pHi or cAMP. Am. J. Physiol. 267:C104-C114.

36. Sokal, R.R., and G.F. Rohlf. 1969. The principles and practice of statistics in biological research. In Biometry. W.H. Freeman, San Francisco. 1050 pp.

37. Hansen, L.K., J.P. Houchins, and J.J. O'Leary. 1991. Differential regulation of HSC70, HSP70, HSP90a, and HSP90b mRNA expression by mitogen activation and heat shock in human lymphocytes. Exp. Cell Res. 192:587-596.

38. Kiang, J.G., M.L. Koenig, and R.C. Smallridge. 1992. Heat shock increases cytosolic free $\mathrm{Ca}^{2+}$ concentration via $\mathrm{Na}^{+}-\mathrm{Ca}^{2+}$ exchange in human epidermoid A431 cells. Am. J. Physiol. 263:C30-C38.
39. Price, B.D., and S.K. Calderwood. 1991. $\mathrm{Ca}^{2+}$ is essential for multistep activation of the heat shock factor in permeabilized cells. Mol. Cell. Biol. 11: 3365-3368.

40. Yamamoto, N., M.W. Smith, A. Maki, I.K. Berezesky, and B.F. Trump. 1994. The role of cytosolic $\mathrm{Ca}^{2+}$ and protein kinase in the induction of the hsp70 gene. Kidney Int. 45:1093-1104.

41. Zimarino, V., C. Tsai, and C. Wu. 1990. Complex modes of heat shock factor activation. Mol. Cell. Biol. 10:752-759.

42. Sorger, P.K. 1991. Heat shock factor and the heat shock response. Cell. 65:363-366.

43. Jurivich, D.A., L. Sistonen, K.D. Sarge, and R.I. Morimoto. 1994. Arachidonate is a potent modulator of human heat shock gene transcription. Proc. Natl. Acad. Sci. USA. 91:2280-2284.

44. Newton, E.M., U. Knauf, M. Green, and R.E. Kingston. 1996. The regulatory domain of human heat shock factor 1 is sufficient to sense heat shock. Mol. Cell. Biol. 16:839-846.

45. Hфj, A., and B.K. Jakobsen. 1994. A short element required for turning off heat shock transcription factor: evidence that phosphorylation enhances deactivation. EMBO (Eur. Mol. Biol. Organ.) J. 13:2617-2624.

46. Kaufmann, S.H.E., and B. Schoel. 1994. Heat shock proteins as antigens in immunity against infection and self. R.I. Morimoto et al., editors. Cold Spring Harbor Laboratory Press, Cold Spring Harbor, NY. 1-30. 